\title{
Supporting students with resits to build self-efficacy
}

\author{
Cath Farrant, Raluca Marinciu, Dawn Reilly, Liz Warren \\ University of Greenwich, UK
}

\begin{abstract}
This project explores the experiences of second-year students on Business School programmes regarding the support available to them in relation to resits in year one. The project involves students as partners in their learning, with data collected via interviews and student discussion forums. Findings are that students who are preparing for resit exams like to use question practice in the resit period to provide mastery experiences which build self-efficacy. We find that students may undervalue feedback on an original submission as a source of guidance towards a resit coursework. The fieldwork was completed before the 2020 campus closure necessitated by the COVID-19 pandemic. However, based on our findings, we suggest recommendations for practice which can be applied for both on-campus and online delivery of our programmes.
\end{abstract}

Keywords: Business Education, exams, inclusivity, mastery experiences, resits, self-efficacy

\section{Introduction}

The aim of this project was to explore the experiences of students in relation to the support which they receive as they prepare for resits. We used the knowledge gained in the project to review our practice in order to improve how we support students. The project involved involving students as partners in their learning, with data collected via student discussion forums and individual interviews with students. The project team was made up of three academic staff from two Business School departments - Accounting and Finance (A\&F), and Human Resources and Organisational Behaviour (HROB) - and a Professional Services colleague. A point to note is that $A \& F$ includes a substantial amount of professional accreditation across its programmes, necessitating a relatively high exam content in the assessment structure when compared to year one of other programmes. On the other hand, HROB students have more essays, a form of assessment which Lizzio and Wilson (2013) state can be challenging for first-year students as they learn what is required in an essay at university level. The project used Bandura's (1999) social cognitive theory as its theoretical lens. Bandura argues that self-efficacious people those who have a higher level of confidence in their own ability - are more likely to succeed in a particular task. The sources of this type of confidence include practising similar tasks (Bandura calls these 'mastery experiences'), being in a good emotional state and being persuaded by others that one can succeed. We used an inductive approach and these self-efficacy themes arose during our analysis of forum and interview data.

Resits provide "a second chance" for students (Ricketts, 2010, p.351). It is essential that we support our students to make the most of that chance as part of an inclusive approach to teaching and learning. Having failed the original assessments, students with resits may lack academic confidence. However, social cognitive theory draws attention to the importance of selfbelief in an individual's learning and development (Bandura, 1999). This positions students as 
potentially powerful agents who can see an improvement in their academic performance because of their own self-reflection and confidence to act. Learning is therefore not dictated only by the external environment because change can be affected through self-belief:

"There is evidence (Bandura, 1997) that self-efficacious students participate more readily, work harder, persist longer, and have fewer adverse emotional reactions when they encounter difficulties than do those who doubt their capabilities" (Zimmerman, 2000, p.86)

Self-efficacy would therefore be a valuable asset for a re-sitting student to develop.

In order to meet the overall aim of the project which was to explore the experiences of students in relation to the support which they received for resit preparation, this paper addresses the following research questions $(\mathrm{RQs})$ :

RQ1: How do we currently support students with resits to improve their self-efficacy?

RQ2: How can we improve that support in the future?

\section{Literature review}

Schmidt et al. (2021) suggest that some students put a low amount of effort into the original assessment because they know there will be a resit opportunity. They then put increased effort into passing the resit. Pell et al. (2009) suggest other reasons which might explain why a student who has failed an original assessment goes on to pass a resit: the experience gained through the original assessment helps a student to pass the resit; there can be 'space' to focus on a single assessment in the resit period; additional tuition can be received before the resit; and a student's emotional response to a resit (for example, fear of failure) can motivate increased effort to pass. An additional opportunity to practise an assessment under exam conditions may be particularly appropriate for, and helpful to, first-year students with an entry qualification less dependent on exam assessment than 'Advanced' (A-) levels - such as a Business and Technology Education Council (BTEC) diploma in the United Kingdom - because they are less used to exams than their peers who followed the more traditional A-level entry route (Hurrell et al., 2019). Resits may, however, pose challenges for some students, such as one who may have missed the original exam rather than failing and therefore cannot benefit from previous experience. Another may have a lot of resits and have to deal with concurrent resit coursework submission deadlines as well. The exam resit period may also be short, pressurising those students who need to take more than one (Proud, 2015). It's true that students may be offered extra tuition in the period leading to the resit, but, for some of them, accessing this type of support face to face may be problematic: around the resit period, they may have competing demands on their time, such as their part-time jobs (vital to them), or be back at home.

Therefore, for the most part, this extra tuition would need to be delivered online and through selfstudy.

The importance of a student's emotional state in passing a resit resonates with Bandura (1997) who identifies an individual's positive emotional state as a source of self-efficacy. Therefore, if students with resits feel anxious, this can have a negative impact on their academic confidence. At that point they may delay starting their revision and subsequently perform poorly in the resit. They might even give up, thinking there is too much for them to retrieve, and decide not to 
engage in the resit opportunity. Bandura (op.cit.) understands how debilitating a poor emotional state can be and argues that a good one is crucial to self-efficacy, but, for him, the best source of efficacy is a 'mastery experience'. Previous success in a situation encourages someone to feel confident about handling similar situations in the future; without that kind of mastery experience, students who have failed an original assessment lack confidence about the resit, believing that they do not have what it takes to pass.

The other sources of self-efficacy identified by Bandura reflect the social nature of learning. A student's academic self-confidence may be built up by positive, affirming comments received from others, such as a lecturer, another student or someone from outside university: family, friends and colleagues. Zimmerman (2000) questions the strength of this source, as that will depend on who is trying to persuade an individual that she or he can succeed and whether the individual believes the persuader. Some students may well benefit from peer encouragement in the run-up to the resits, but others may not want to talk to anyone or admit that they have to resit. Self-efficacy can also arise vicariously: seeing your peers succeed may lead to a growth in confidence that you can do it too, though Zimmerman (op.cit.) again doubts whether this works for all. He suggests that a re-sitting student might discount the relevance of other students' positive assessment achievements if $\mathrm{s} /$ he perceives them as more able.

Klassen et al. (2008) suggest that self-efficacious students are less likely to indulge in 'academic procrastination' - a delay in starting to study, with a consequent adverse effect on performance. This is linked to the moderating effect of the amount of time spent on task noted by Honicke and Broadbent (2016) and is very relevant in the case of a student with resits. A delay in starting to study, whether in order to complete a piece of resit coursework or to revise for a resit exam, results in a reduction of time spent on that activity and, consequently, less likelihood of success. Honicke and Broadbent (op.cit.) also identify the mediating factor of goal-setting. This partially explains the relationship between self-efficacy and performance because a confident student is more likely to set study goals and then work hard to achieve those goals, so improving performance. As argued by Proud (2015, p. 696):

"... a resit alone would not necessarily lead to any improvement in outcomes. ... we need to ensure that the incentives are there for students to put in an appropriate level of work for their resit examination."

\section{Methodology}

We used semi-structured individual interviews and group discussion forums to explore students' views on the resit support which we currently provide and to consider their suggestions for the future. This project took place in the 2019-20 academic year. It should be noted that the discussion forums and interviews were carried out in the period November 2019 to February 2020, before the campus closure necessitated by COVID-19. Our fieldwork was therefore not affected by the pandemic. Furthermore, the data collected from students related to their experience of resit support in the previous academic year.

The interviews and forums were audio-recorded, transcribed, and analysed using NVivo software. The research was inductive; social cognitive theory emerged as providing a suitable theoretical lens for the project during the analysis phase as self-efficacy themes emerged from the interview and forum data. Approval for the project was received from the University's research ethics committee before fieldwork began. 
We used interviews in order to explore students' experiences and collect in-depth information. Participants had experienced resits on their programmes and, for some students, the fact that they had been required to re-sit might have been a sensitive issue which they would not want to talk about in front of other students. The interviews were therefore one-to-one, like those of Scott and Graal (2007), who used individual interviews with thirteen students who had failed modules in the first year of their programmes. In our study, fifteen students participated in a one-to-one interview to speak about their experiences of resit support on their programmes. Because the project team included colleagues from two departments, we offered each student the choice of talking either to someone who had taught on their programme or someone who had not. All participants chose the former which provided a consistent approach. McGrath et al. (2019) highlight the possible effect of students' perception of the lecturer-student power dynamic, which may lead them to give answers they think their lecturers wish to hear. To reduce this risk, interviewers reassured participants that they should feel free to answer honestly and that their comments would be anonymised. Specifically, participants were reassured that their comments would not be communicated to other lecturers. The interviews were semi-structured to enable interviewers to explore the points which arose. The initial questions are shown in figure 1.

\section{Figure 1: Questions for semi-structured interviews with students}

Please tell me about your experience of resits while you have been at the University. How did you prepare for the (exam $X)$ resit? How did you prepare for the (coursework $Y$ ) resit?

What was different in the resits which meant that you passed?

Which sources of resit support did you use?

If you could suggest one additional thing either the University or your lecturers could do to support students with resits, what would that be?

Thirty-two students participated in six discussion forums. Because a motivation for the project was to gain insight into the existing resit support system for year one, the students in the forums were second years, so allowing us to investigate their knowledge of the resit support which we provide for students in the first year. Because the number of students who had been required to re-sit was a relatively small proportion of the cohort and because some of those might feel the stigma of having had to do so, we thought it inappropriate to advertise for forum participants by singling out re-sitters. Therefore, we opened the forums to the whole year group.

The design of the discussion forums drew on Colucci (2007) and included activities intended to encourage discussion among students. The activities did not require participants to disclose if they had taken resits in year one. Activity 1 was a free listing, with each group asked: "What support is available for students with coursework or exam resits?" We provided students with sticky notes and asked them to write down on those the different sources of support they were aware of and to stick the notes on to a large sheet of paper. As the students wrote their suggestions, the facilitator encouraged them to discuss these in their group. Starting the discussion in this way ensured that students were able to give their views without being restricted or directed by any preconceived ideas of the project team. Activity 2 was a ranking exercise, with students given eight pre-identified sources of support and asked to rank those in 
order of usefulness from 1 (most useful) to 8 (least useful). These eight sources of support are shown in table 1. Students were also allowed to include any other sources which they had identified in the initial free listing activity, but no group chose to do that. In the process of negotiating the order of the ranking, students discussed their views on the different sources of support available. Their having done that, we asked the students as their final (third) activity to discuss their answers to this question: "Is there one additional thing we could do to support students with coursework resits or exam resits?"

\section{Results}

At the beginning of the discussion forums, in activity 1, each group was asked to list the sources of resit support available to them. In addition to the eight sources already identified before the forums (table 1), students noted support from the University's central wellbeing team, email correspondence with lecturers and teaching material from throughout the year (lecture slides, textbooks or module handbooks). Only two groups mentioned feedback on an original assignment as a source of resit support. None of the groups took the opportunity to bring any of these extra items into the ranking exercise comprising activity 2 . The rankings for activity 2 for the six groups, together with an average overall ranking, are shown in table 1 . The overall result was that revision material on the University's virtual learning environment (VLE) was perceived as the most useful, followed by the closely related item of past exam papers, which are also available on the VLE. Support from personal tutors was identified as the least useful source in the ranking exercise. However, this may have been because personal tutors often signpost other sources of support in their conversations with students (for example, the wellbeing team for counselling services, the academic skills team for study skills, or module leaders for technical content) and students might have overlooked or undervalued the importance of listening, understanding, and signposting to the appropriate support. In activity 3 , students suggested that it would be useful to have access to more past exam questions and recordings to explain the solutions to those questions. In addition, one group suggested that re-sitting students would benefit from support with motivation and wellbeing.

Table 1. Student forum (SF) rankings of sources of support

$$
1=\text { most useful to } 8 \text { =least useful }
$$

\begin{tabular}{|l|l|l|l|l|l|l|l|l|}
\hline & $\begin{array}{l}\text { Overall } \\
\text { ranking }\end{array}$ & Mean & SF1 & SF2 & SF3 & SF4 & SF5 & SF6 \\
\hline Revision material on the VLE & 1 & 2.58 & 1 & 2 & 4.5 & 1 & 4 & 3 \\
\hline Past exam questions and solutions & 2 & 2.75 & 3 & 1 & 4.5 & 2 & 5 & 1 \\
\hline $\begin{array}{l}\text { Face-to-face revision session in } \\
\text { the summer }\end{array}$ & 3 & 3 & 2 & 4 & 1 & 6 & 3 & 2 \\
\hline Support from the module leader & 4 & 4.5 & 5 & 3 & 6 & 5 & 1 & 7 \\
\hline $\begin{array}{l}\text { Short Panopto recordings on key } \\
\text { topics }\end{array}$ & 5 & 5 & 7 & 7 & 2.5 & 3.5 & 6 & 4 \\
\hline Panopto recordings of lectures & $6=$ & 5.67 & 8 & 8 & 2.5 & 3.5 & 7 & 5 \\
\hline $\begin{array}{l}\text { Support from the Academic skills } \\
\text { team in the library }\end{array}$ & $6=$ & 5.67 & 4 & 6 & 8 & 8 & 2 & 6 \\
\hline Support from your personal tutor & 8 & 6.83 & 6 & 5 & 7 & 7 & 8 & 8 \\
\hline
\end{tabular}

Comments made by students in the interviews (I) and student forums (SF) are set out in the remainder of this section. The comments are grouped under the themes which emerged during our analysis of the data collected. These themes include three sources of self-efficacy (mastery 
experiences, emotional state and verbal persuasion) and particular reasons for academic procrastination which students identified as relevant in the resit period.

\section{Mastery experiences}

For exam resits, students commented on how useful they found past papers for practice in order to pass a resit exam:

"I just went through exam papers, looking at exam papers, thinking this might turn up, ... and studying those topics thoroughly and then sitting the exam." (I 1)

"Before the first exam, I didn't check the past papers and then as soon as I did the exam, I went to past papers ... I did the exam and then I went through three years, I think, of past papers..." (I 2)

"I felt like I could just do continuous on past papers and, you know, do better in my exams." (I 3)

Students explained what was different about their approach to the resits that meant that they passed: their increased efforts to achieve mastery experiences often cropped up. Some were motivated by the knowledge that the resits were a final opportunity to pass the year, for both coursework and exams:

"I had a sense of urgency so I knew what I had to do and feel like what I had to do. So for example on my first ... course work I sort of left out a few things that I didn't know but in the resit I went through it and I went through the slides and previous slides on what to do ... I probably went through it [the material on the VLE] more thoroughly during the resit time." (I 4)

"... I knew I had to pass the first time but this time I was like, okay I have to work harder. When I didn't pass the first time, I actually thought I was going to have to retake the whole year... it was my only opportunity to actually go through to next year." (I 5)

"I would say there was a difference because with my resits, I knew that this was the only chance so I was more determined and more focused whereas the original ones as much as I was focused, I wasn't. I would say that because I always knew I had got a second chance, I didn't take it as seriously as I should have." (I 3)

\section{Emotional state}

The resit period can be a demotivating time for some students:

"... people that don't pass the first time, they automatically feel demotivated, it puts them down. People can take it two different ways. Obviously, it would either motivate them or it would just demotivate them and it will either help them to work harder or they will just stop and not bother at all. So I feel like the majority of the people, they have that mentality, that okay l've failed, what's the point?'

A lack of confidence also stopped students asking for help from their lecturers or attending faceto-face revision sessions: 
"Well, the people I knew, they just thought, well we've failed anyway. They didn't think that they had a chance... They just felt like they weren't going to do it, so they didn't want to bother." (I 6)

"I don't want to do this embarrassment, I don't want people to see me coming back at uni in July, I don't want anyone asking me questions. People think like this and that was me, to be honest... I remember at the time definitely feeling overwhelmed... that feeling of being overwhelmed then actually prevents me from seeking help, which was obviously the complete opposite and the worst thing to do when there are people out there trying to reach out to you to support you. Unfortunately, I did the opposite at the time and just that feeling of I am not good enough to do this at the time." (I 7)

"... when you are at uni, you are sort of in a structure and format so you know it is organised up to the exam... when you do the resits, I guess you don't really have that formal structure. So I guess in my case I had to actually go and approach the people that are head of each course and ask for a bit of advice." (I 8)

During the resit period students would benefit from being proactive and confident about seeking help from their lecturers. However, for a first-year student, it can be particularly difficult to ask a lecturer for help; second years might be more confident about doing that.

\section{Verbal persuasion}

In the forums, one group noted that the motivation to engage with resits can come from other students:

"We need more people to encourage them because I think everyone loses hope. Exams are not easy. I haven't passed that one, how would I manage to pass the next one? ... People like having revision so you can have a kind of group revision. You can cover it with the others and get a better explanation. That's my opinion. You can never be $100 \%$ good in a topic or in a specific module so there'll be a module or topic where you'll be lacking and don't have knowledge of it like in the other modules. So you can share that with the people who are having difficulty with it... I think when you do a resit, you go to the library and it's not only you doing the resits so you literally get knowledge together other than what we got from the University." (SF 4)

\section{Academic procrastination}

For some, it is difficult to find the time or motivation to study in the resit period because of the timing; for example, when a resit is in July. First, the resit period is after teaching ends and there are holidays and events which can provide a distraction from studying:

"I wasn't actually in the country, so that was a little difficult. I had to go back to my country for a wedding and trying to put my family aside and doing the work for the resubmission, that was a little bit difficult." (I 9)

"Actually when I started my preparation, I was in Spain on the... summer school so after uni I had to go to our accommodation for about two hours, practise... where I went wrong and how to improve with it. And then when I come back to London that is when I actually 
came to uni and started to do the coursework and actually do the work and submit them."

(I 4)

The summer is when some students need to work more hours in their part-time jobs to help to fund their studies, making it more difficult to study with their peers in the resit period:

“... during the whole break, I was working two jobs, for a few months." (I 10)

"I was doing work on my own because I was working as well..." (I 6)

Having analysed the results of the interviews and discussion forums, using themes provided by the literature on self-efficacy, we now discuss the findings.

\section{Discussion}

That the students who agreed to participate in an interview had passed their resits could be deemed self-selection bias, because we did not interview any students who had failed their resits. However, the majority of re-sitting students pass and therefore participants represent a significant group. This group might also be assumed to include those students who were motivated to try to pass their resits and eager to use the support available. Therefore, their experiences provide insight into students' views on the resit support we provide. There were incidences where students had felt despondent about their resits but, for the most part, students talked about what they had done differently in the resits in order to succeed, especially for exam assessments. In accordance with Arnold (2017), a few students indicated that they worked harder for the resits. This was because they had limited the effort they expended on the original assessments, being aware that there would be a resit opportunity if needed. Revision material and past exam papers were noted by students as important sources of resit support for exam assessments. These enabled the mastery experiences which Bandura (1997) argues are the most important source of self-efficacy. If students were to focus only on selected questions from past papers, taking a strategic approach to practising exam technique, the result would be surface learning. However, in interviews and discussion forums, students indicated that, along with past papers, they use revision material and other materials provided through the year, this suggesting that a deeper level of learning is going on in many cases. It is interesting to note that students put personalised support from academic skills advisers and personal tutors lowest in the forum rankings. Students value online resources that are accessible and digestible. We should, of course, continue to offer personalised support during the resit period but we also need to focus on providing appropriate online resources that students can go back to.

This project uses a broad definition of resit support which includes all teaching materials, academic relationships, guidance and feedback that are intended to help a re-sitting student to engage and succeed in a resit assessment. For resit coursework, only two forums identified feedback on the original submission as a source of resit support. The literature documents that not all students read or learn from their feedback (O'Donovan et al., 2016; Carless et al., 2011). Students may read their original feedback when it is first received, looking for justification for a fail grade (Winstone et al., 2017) but they can then disregard it and overlook its usefulness to their preparation for a resit assignment. However, as this feedback should be a useful resource for a re-sitting student to improve her/his work, it can be considered part of the resit support which we provide, especially if a lecturer initiates a review and explanation of this feedback in the resit period. 
A good emotional state is a source of self-efficacy. It is therefore important to help students to deal with any negative feelings about resits. This can be difficult when a resit period is during the holidays after teaching has ended. Another point to note in relation to coursework is that although the resit period is in the summer, some students start to worry about a future resit as soon as they receive the original mark - so there is an opportunity to speak to students to try to help them while they are on campus.

Negative emotions can stop students interacting with their peers and lecturers, who can be useful sources of self-efficacy if they provide encouragement that a student can succeed. An important source of verbal persuasion on a student's programme of study is peer support, including that available from informal study groups of friends. However, the other members of a friendship group might not have resits and therefore would not be available for informal group study sessions in the summer. In the resit period, there is limited interaction between lecturers and students and yet this is when re-sitting students need encouragement to believe in themselves because, as Zimmerman (2000, p.89) concludes, "students' self-beliefs about academic capabilities do play an essential role in their motivation to achieve".

In the resit period, most students are not on campus. They can also be on holiday or working extra hours in their part-time jobs while there are no classes. This presents a problem for students with resits who might procrastinate academically, especially when they lack confidence about passing the resits. The delay in starting resit exam revision or working on resit coursework increases the probability that they will not perform well.

\section{Conclusion}

This study has identified sources of self-efficacy for students with resits. Since re-sitting students might not go into the resit period feeling confident, it is important to identify effective sources of self-efficacy to consider how we can encourage future students who have resits and support them to succeed. For students with resit exams, it is relatively straight forward for them to engage in mastery experiences using teaching material, revision exercises and past papers on the VLE. However, during the resit period, it can be challenging for students to find emotional support if they are feeling nervous or anxious about their assessments when they are at home. There can also be misunderstandings regarding the support which is available from module leaders and personal tutors during the holiday period. This problem is amplified because, over the summer, students are less likely to check their university email accounts, either through forgetfulness, the busyness of life with summer jobs or perhaps not wanting to face reality regarding their academic performance.

Our investigation has found many examples of good practice in support for re-sitting students in both departments. Our fieldwork was carried out in the period before the 2020 campus closure when there was a clear distinction between on-campus teaching towards the original assessments and the resit period. However, we shall attempt to look forward and present five recommendations for practice which can be applied in both on-campus and blended delivery modes.

The first recommendation from the project concerns communication. We suggest that our communication about resits should start during term time when students are more engaged with their university emails, even though this is before a student's resits are confirmed. Institutions should review their messages and communications to students about the process of resits and 
the structure of support provided, because this can be used to de-stigmatise resits. However, designing this type of message is not straightforward because it should be balanced with the need not to be seen as promoting resits as 'Plan A', especially where the resit grades will be capped. A second recommendation is the need for academics to reach out to individual students with resits, perhaps more than once, to try to make contact and offer support over the holiday period. Specifically, where a student has a coursework resit, a tutor should contact the student in the resit period to remind the student about the feedback on an original assignment and offer to explain it. A third recommendation is to be mindful of the importance of revision material and past papers to students. They can use these to gain mastery experiences ahead of a resit exam. Therefore, we need to ensure we provide enough material of this type. Fourth, the student forums showed that there was a slight preference for short videos over live recordings of whole lectures as revision material. If we extrapolate this finding to our increased provision of recordings as part of a blended or online delivery, this suggests that some students prefer a lecture to be broken down into smaller parts to aid learning.

A final recommendation is the need to define what is meant by 'resit support' so that we can identify the range of support materials, feedback and encouragement available, and promote that to students. This project has offered a broad and inclusive definition of resit support which includes all the teaching materials, academic relationships, guidance and feedback intended to help a student to engage and succeed in a resit assessment.

A limitation of this project is that it was set in one context and included only a small number of students. Future research in different settings and with larger numbers of participants would be useful for exploring the issue in more depth. This could include comparing the views of students on different programmes and listening to the voices of students who failed their resits. The support provided to re-sitting students is an under-researched area, but it is extremely important because there are students who need an extra helping hand to guide them through their resits. Our hope is that this paper encourages further research which will build our knowledge of this important aspect of inclusive teaching and learning to benefit future cohorts of students.

\section{Acknowledgment}

The investigation received internal funding as a learning and teaching project.

\section{Reference list}

Arnold, I. (2017) 'Resitting or compensating a failed examination: Does it affect subsequent results?' Assessment \& Evaluation in Higher Education, 42(7), 1103-1117. Available at: https://www.tandfonline.com/doi/full/10.1080/02602938.2016.1233520 (Accessed: 01 June 2021).

Bandura, A. (1999) 'Social cognitive theory: An agentic perspective.' Asian Journal of Social Psychology, 2(1), 21-41. Available at: https://onlinelibrary.wiley.com/doi/pdf/10.1111/1467839X.00024?saml referrer (Accessed: 01 June 2021).

Bandura, A. (1997) Self-Efficacy: The Exercise of Control. New York: W. H. Freeman. ISBN: 978-0716728504

Compass: Journal of Learning and Teaching, Vol 14, No 2, 2021 
Carless, D., Salter, D., Yang, M. and Lam, J. (2011) 'Developing sustainable feedback practices.' Studies in Higher Education, 36(4), 395-407. Available at:

https://www.tandfonline.com/doi/full/10.1080/03075071003642449 (Accessed: 01 June 2021)

Colucci, E. (2007) 'Focus groups can be fun: The use of activity-oriented questions in focus group discussions.' Qualitative Health Research, 17(10), 1422-1433. Available at: https://journals.sagepub.com/doi/pdf/10.1177/1049732307308129 (Accessed: 01 June 2021).

Honicke, T. and Broadbent, J. (2016) 'The influence of academic self-efficacy on academic performance: A systematic review.' Educational Research Review, 17, 63-84. Available at: https://www.researchgate.net/publication/289378553 The Influence of Academic SelfEfficacy on Academic Performance A Systematic Review (Accessed: 01 June 2021).

Hurrell, E., Shawcross, E. and Keeling, E. (2019) 'How does a vocational qualification (BTEC) prepare students for a degree in Biosciences at a research intensive university?' New Directions in the Teaching of Physical Sciences, 14(1). Available at:

https://www108.lamp.le.ac.uk/ojs1/index.php/new-directions/article/view/3315/3032 (Accessed: 01 June 2021).

Klassen, R., Krawchuk, L. and Rajani, S. (2008) 'Academic procrastination of undergraduates: Low self-efficacy to self-regulate predicts higher levels of procrastination.' Contemporary Educational Psychology, 33(4), 915-931. Available at: https://www.sciencedirect.com/science/article/pii/S0361476X07000264 (Accessed: 01 June 2021)

Lizzio, A. and Wilson, K. (2013). 'First-year students' appraisal of assessment tasks: Implications for efficacy, engagement and performance.' Assessment \& Evaluation in Higher Education, 38(4), 389-406. Available at:

https://www.tandfonline.com/doi/full/10.1080/02602938.2011.637156 (Accessed: 01 June 2021).

McGrath, C., Palmgren, P. and Liljedahl, M. (2019) 'Twelve tips for conducting qualitative research interviews.' Medical Teacher, 41(9), 1002-1006. Available at: Full article: Twelve tips for conducting qualitative research interviews (tandfonline.com) (Accessed: 01 June 2021).

O'Donovan, B., Rust, C. and Price, M. (2016) 'A scholarly approach to solving the feedback dilemma in practice.' Assessment \& Evaluation in Higher Education, 41(6), 938-949. Available at: https://www.tandfonline.com/doi/full/10.1080/02602938.2015.1052774 (Accessed: 01 June 2021).

Pell, G., Boursicot, K. and Roberts, T. (2009) 'The trouble with resits...' Assessment \& Evaluation in Higher Education, 34(2), 243-251. Available at: https://www.tandfonline.com/doi/full/10.1080/02602930801955994 (Accessed: 01 June 2021).

Proud, S. (2015) 'Resits in higher education: Merely a bar to jump over, or do they give a pedagogical 'leg up'?' Assessment \& Evaluation in Higher Education, 40(5), 681-697. Available at: https://www.tandfonline.com/doi/full/10.1080/02602938.2014.947241 (Accessed: 01 June 2021). 
Ricketts, C. (2010) 'A new look at resits: Are they simply a second chance?' Assessment \& Evaluation in Higher Education, 35(4), 351-356. Available at:

https://www.tandfonline.com/doi/full/10.1080/02602931003763954 (Accessed: 01 June 2021).

Schmidt, H., Baars, G., Hermus, P., van der Molen, H., Arnold, I. and Smeets, G. (2021)

'Changes in examination practices reduce procrastination in university students.' European Journal of Higher Education, 1-16. Available at:

https://www.tandfonline.com/doi/full/10.1080/21568235.2021.1875857 (Accessed: 01 June 2021).

Scott, J. and Graal, M. (2007) 'Student failure in first year modules in the biosciences: an interview based investigation. Bioscience Education, 10(1), 1-8. Available at:

https://www.tandfonline.com/doi/full/10.3108/beej.10.c2 (Accessed: 01 June 2021).

Winstone, N., Nash, R., Rowntree, J. and Parker, M. (2017) 'It'd be useful, but I wouldn't use it": barriers to university students' feedback seeking and recipience.' Studies in Higher Education, 42(11), 2026-2041. Available at:

https://www.tandfonline.com/doi/full/10.1080/03075079.2015.1130032 (Accessed: 01 June 2021).

Zimmerman, B (2000) 'Self-efficacy: An essential motive to learn.' Contemporary Educational Psychology, 25(1), 82-91. Available at:

https://www.sciencedirect.com/science/article/pii/S0361476X99910160 (Accessed: 01 June 2021). 